\title{
Author Correction: A Dynamic Approach to Risk Factors for Maternal Corporal Punishment in Early to Middle Childhood
}

\author{
Leyco M. Wilson ${ }^{1} \cdot$ Michael F. Lorber ${ }^{2} \cdot$ Patti A. Timmons Fritz ${ }^{3}$
}

Published online: 16 January 2018

(c) Springer Science+Business Media, LLC, part of Springer Nature 2018

Correction to: Journal of Child and Family Studies (2017) https://doi.org/10.1007/s10826-017-0929-8

The original version of this article unfortunately contained a mistake. In the second sentence of the Abstract section the word "Fragile" was missing. It should read as "Archival data from Fragile Families and Child Wellbeing Study..."

The original article can be found online at https://doi.org/10.1007/ s10826-017-0929-8.

Leyco M. Wilson

Leyco.Wilson@facswaterloo.org

1 Department of Psychology, University of Windsor, 401 Sunset Avenue, Windsor, Ontario N9B 3P4, Canada

2 Family Translational Research Group, New York University, 137 East 25th Street, 6th Floor, New York, NY 10010, USA

3 Department of Psychology Assistant Dean of Graduate Studies, Faculty of Arts, Humanities, and Social Sciences, University of Windsor, 401 Sunset Avenue, Windsor, Ontario N9B 3P4, Canada 